\title{
Enhancing the oxidation resistance of copper by using sandblasted copper surfaces
}

Lu Yuan, Xiaoming Chen, Suraj Maganty, Junghyun Cho, Changhong Ke, Guangwen Zhou*

Department of Mechanical Engineering \& Multidisciplinary Program in Materials Science and

Engineering, State University of New York, Binghamton, NY 13902, USA

\begin{abstract}
We show that sandblasting can be employed to effectively enhance the oxidation resistance of copper by suppressing the interfacial delamination between copper and its oxide by modifying the surface roughness of $\mathrm{Cu}$. Increasing sandblasting treatment time from 0 to $120 \mathrm{~s}$ increases the surface roughness of $\mathrm{Cu}$ from $0.12 \pm 0.003 \mu \mathrm{m}$ to $2.89 \pm 0.176 \mu \mathrm{m}$, which results in improved oxidation resistance of the $\mathrm{Cu}$ surfaces and enhances the oxide/substrate interfacial fracture energy from 0.035 $\mathrm{J} / \mathrm{m}^{2}$ to $3.1 \mathrm{~J} / \mathrm{m}^{2}$ determined using nanoindentation. The sandblasting treatment has no appreciable effect on the Young's moduli of the Cu oxide film, which remain nearly constant at around $36 \mathrm{GPa}$. The improved oxidation resistance is ascribed to the enhanced interfacial adhesion of the sandblasted copper owning to the concave shape of craters generated by sandblasting, which results in a net downward force from the compressive stresses in the oxide film that forces the film to adhere to the $\mathrm{Cu}$ substrate.
\end{abstract}

Key words: Copper; Oxidation; Sandblasting

*To whom correspondence should be addressed. E-mail: gzhou@binghamton.edu 


\section{Introduction}

The macroscopic separation of a protective oxide film from a metallic substrate is a chronic problem in the oxidation of metallic materials, resulting in poor oxidation resistance mainly because of the poor adhesion between the oxide film and the metal substrate due to the mismatch in their specific volumes and thermal expansion coefficients. This is exemplified by the oxidation of copper $(\mathrm{Cu})$, which has been considered as a major reliability problem in electronic devices. As semiconductor packaging is rapidly heading towards higher integration and decreased sizes, $\mathrm{Cu}$ along with its wide variety of alloys has been increasingly used as an interconnect material (e.g. lead frame) for microelectronic industry owing to its high electrical and thermal conductivities and low cost [1-5]. However, the applications of $\mathrm{Cu}$ and $\mathrm{Cu}$ alloys have been limited by the oxidation of $\mathrm{Cu}$ during the packaging assembly process due to their high affinity for oxygen, which makes them susceptible to oxidation when subject to elevated temperatures $[2,6,7]$. Unlike aluminum oxide, the $\mathrm{Cu}$ oxide layer is not self-protective and the oxidation of $\mathrm{Cu}$ continues $[8,9]$. This usually results in delamination that decreases the adhesion between the lead frame and epoxy-molding compound (EMC) [10-13]. Cu oxidation is considered as a major reliability problem for the development of high-density integrated circuit packages and lead-free soldering. A main cause for the low adhesion of lead frame $\mathrm{Cu}$ with EMC is the low adhesion between the $\mathrm{Cu}$ substrate and the Cu oxide film formed from the oxidation $[2,10,11]$.

Significant effort has been made towards improving the interfacial adhesion between the $\mathrm{Cu}$ based substrate and EMC in order to achieve high reliability of electronic packages, especially for those used in harsh environments such as the automobile and aerospace industries. It mainly involves modifying the chemistry and topography of the $\mathrm{Cu}$ surfaces [14-16]. Cu surface chemistry has been modified primarily through plating with metals. A main function of plating is to reduce the growth of $\mathrm{Cu}$ oxide films during the packaging processes that are detrimental to adhesion. Several plating materials include $\mathrm{Ag}, \mathrm{Au}$, and $\mathrm{Pd}[2,17,18]$ have been used with varying degrees of success. Modification in 
surface topography is based on the principle of mechanical interlocking to improve the interfacial adhesion by introducing tiny holes or dimples etched on the $\mathrm{Cu}$ surface $[2,18,19]$. The pin-shaped molding compound entrapped within these holes provides an interlocking mechanism that prevents large-scale delamination.

Aside the aforementioned remedies for improving the delamination performance, a more fundamental approach is to directly improve the adhesion between the $\mathrm{Cu}$ substrate and the Cu oxide films formed during oxidation. Oxide/substrate adhesion exerts a decisive influence on the oxidation resistance of a material. Poor adhesion usually leads to oxide cracking, flaking or even exfoliation from the substrates due to the specific volume misfit between the oxide layer formed during oxidation and the metal substrate, resulting in the failure of the oxidation resistance protection $[8,20]$. Adhesion is a mechanical factor based on the surface topography and can be described as the interface fracture energy; the larger the surface, the higher the interface fracture energy and consequently the better the adhesion [21]. It has been shown that surface treatment by simple mechanical approaches such as grinding, polishing, and sandblasting can play a dramatic role in changing the progress of oxidation [2224]. For instance, Yuan et al. studied the effect of surface finish on the scaling behavior of a stainless steel and found that surface deformation improved the oxidation resistance [23]. Tan et al. noted that shot-peening processing is an effective approach to improve the oxidation resistance of boiler steel [24]. However, the effect of such surface treatments on the oxide/metal adhesion is not addressed in the oxidation of $\mathrm{Cu}$ and there is a considerable lack of quantitative measurements on the interfacial adhesion energy of $\mathrm{Cu}$ and its oxide formed from the oxidation of the $\mathrm{Cu}$ surfaces treated by different mechanical approaches. In this work, we employ sandblasting to increase the surface roughness of $\mathrm{Cu}$ surfaces and examine the effect of the sandblasting on oxidation kinetics of the $\mathrm{Cu}$ surfaces. We demonstrate the unequivocal effects of the increased surface roughness on the enhanced oxide/substrate adhesion. Particularly, the quantitative correlation between the oxide/metal interfacial 
fracture energy and the surface roughness of the Cu substrate treated by sandblasting is established by nano-indentation measurements.

\section{Material and Methods}

High-purity Cu foils (99.99\% purity) with a thickness of $0.25 \mathrm{~mm}$ (obtained from Sigma-Aldrich, St. Louis, MO) are used in the oxidation experiments. Sandblasting is very simple and low-cost process for mechanical surface treatments. In our experiments, a high-pressure gun is used for bombarding the Cu surfaces with glass beads. The sandblasting experiment is conducted in a glove box that allows for recycling and reuse of the glass beads. The sandblasting nozzle has a diameter of $1 / 4$ inch and the working distance from the sample surface is about $\sim 20 \mathrm{~cm}$. The metal foils are first sandblasted by glass bead abrasive with a diameter range of $150 \sim 250 \mu \mathrm{m}$ at the pressure of $\sim 50$ psi on both sides with different time durations to modify the surface morphologies and roughness. The sandblasted samples are then cleaned with $0.1 \mathrm{M} \mathrm{HCl}$ to remove the native oxide layer and then thoroughly rinsed with deionized water for $10 \mathrm{~min}$ followed by ultrasonication in acetone for $5 \mathrm{~min}$. The cleaned $\mathrm{Cu}$ substrates are dried in $\mathrm{N}_{2}$ for further analysis. Cleanliness of the cleaned surface was examined by optical microscopy and scanning electron microscopy (SEM), which barely show any residual glass beads. The surface roughness of the sandblasted $\mathrm{Cu}$ is measured using an optical profiler (WYKO NT1100). The oxidation kinetics of the Cu substrates is measured by TGA - TA Instruments Q50. Each Cu substrate is placed in an alumina crucible and heated from room temperature up to $450^{\circ} \mathrm{C}$ at a heating rate of $20^{\circ} \mathrm{C} / \mathrm{min}$ and then kept at $450{ }^{\circ} \mathrm{C}$ for $1 \mathrm{~h}$ in a flow of pure oxygen $(60 \mathrm{ml} / \mathrm{min}$ ) during the TGA measurements. An empty pure alumina crucible serves as an inert reference for measuring the mass gain. It is worth mentioning that the choice of $450{ }^{\circ} \mathrm{C}$ and pure oxygen in our experiments represents an accelerated test for the oxidation of the system in service, which allows for elucidating the effect of sandblasting on the interface adhesion strength between the Cu substrate and the oxide film. This oxidation condition is not 
representative for the actual device fabrication processes because the entire $\mathrm{EMC} / \mathrm{Cu}$ interface may be not equally exposed to oxygen in practice. The surface and interfacial morphologies of the oxidized samples are examined using an optical microscope (Zeiss Axiovert $200 \mathrm{M}$ ) and a field-emission gun scanning electron microscope (FEG-SEM) FEI Supra 55VP. The nanoindentation measurements are employed to measure the oxide/substrate adhesion. In this study, all the nanoindentation measurements are performed using the TriboScope Nanoindenter (Hysitron Inc., Minneapolis, MN) with a sharp three-sided pyramidal diamond berkovich indenter. The oxide/metal interfacial adhesion force is quantitatively measured by the nanoindentation test, which consists of a constant-rate-loading segment, a hold segment, and a constant-rate-unloading segment. The oxide film under indenter tip is first loaded to a prescribed force (maximum force) with a constant rate of $0.5 \mathrm{mN} / \mathrm{s}$. The load is then held at the maximum value of loading for $5 \mathrm{~s}$ in order to avoid delayed deformation. The indenter is then withdrawn from the oxide film surface at $1 \mathrm{mN} / \mathrm{s}$ in a similar force controlled mode until it is completely out of contact with the surface. In the measurements, a series of continuous load-unload indentations with a maximum load of $7 \mathrm{mN}$ are carried out at different locations of the oxidized $\mathrm{Cu}$ surface and the distance between the different locations is kept at least $100 \mu \mathrm{m}$ apart to avoid interaction between the indented areas. All measurements are performed at room temperature on the post-oxidized samples.

\section{Results and Discussion}

Sandblasting is a common mechanical procedure providing repeated impacts on a surface at a high speed and is widely used in metal and alloy treatments. Sand spheres of specific diameters are propelled through a pressurized gun and hit the surface of the metal. The sandblasting can generate compressive residual stresses and high-density dislocations in the target substrate, resulting in increased surface roughness and concave craters $[25,26]$. The surface morphology and roughness average (Ra) of the sandblasted Cu substrates are measured by an optical profiler. Figs. 1(a-e) show the typical optical 
profiler 3D surface morphology images of the $\mathrm{Cu}$ substrates treated by sandblasting with different durations. It can be seen that the un-sandblasted $\mathrm{Cu}$ (i.e., 0 s) shows a smooth surface (Fig. 1(a)). Fig. 1(b) corresponds to the Cu surface treated by sandblasting for $15 \mathrm{~s}$, which reveals the presence of several craters created by energetic glass beads. Increasing the sandblasting time results in the formation of overlapped craters, as shown in Figs. 1(c-e). Fig. 1(f) shows the dependence of the surface roughness of the $\mathrm{Cu}$ substrates on the sandblasting treatment durations, which shows that the surface roughness increases from $0.12 \pm 0.003 \mu \mathrm{m}$ to $2.89 \pm 0.176 \mu \mathrm{m}$ with sandblasting time.

TGA analysis is employed to monitor the oxidation kinetics of the $\mathrm{Cu}$ substrates which are first treated by sandblasting with different durations. Fig. 2 shows the mass gains of the Cu substrates as a function of time during the oxidation at $450{ }^{\circ} \mathrm{C}$ for $1 \mathrm{~h}$ in an oxygen flow of $60 \mathrm{ml} / \mathrm{min}$ (including the temperature ramping from room temperature to $450^{\circ} \mathrm{C}$ at a rate of $20^{\circ} \mathrm{C} / \mathrm{min}$ ). It shows that the weight change for the flat $\mathrm{Cu}$ substrate (i.e., un-sandblasted $\mathrm{Cu}$ ) grows slower than the sandblasted $\mathrm{Cu}$ samples in the first $\sim 30 \mathrm{~min}$ (as shown in the insert zoom-in plots), then increases faster than the sandblasted samples. The initially faster oxidation rate for the sandblasted samples can be attributed to the sandblasting-generated surface deformations, which facilitate oxide nucleation and growth compared to the un-sandblasting $\mathrm{Cu}$. As oxidation continues, the oxide/substrate adhesion becomes an important factor in the oxidation rate. For un-sandblasted $\mathrm{Cu}$, the oxide film can easily delaminate from the substrate, which results in the exposure of new $\mathrm{Cu}$ surface areas to oxygen for further oxidation. For sandblasted $\mathrm{Cu}$, the oxide film is more adherent to the $\mathrm{Cu}$ substrate and thus can effectively block the supply of oxygen to the oxide/metal interface region. Therefore, the improved oxide/substrate interface adhesion slows down the oxidation rate as the reaction progresses. For the samples treated by sandblasting with different durations, the trend for the dependence of the initial oxidation rate on sandblasting time is not very clear. However, the TGA results indicate clearly that increasing the 
sandblasting time leads to a decrease in the oxidation rate of the $\mathrm{Cu}$ substrates for the longer oxidation time, i.e., the overall oxide growth rate is reduced with increasing sandblasting treatment time.

The surface morphologies of the oxidized Cu substrates are analyzed by optical microscopy. The $\mathrm{Cu}_{2} \mathrm{O} / \mathrm{Cu}$ interfacial delamination results in exposed $\mathrm{Cu}$ surfaces that appear in orange under the optical microscope. Fig. 3 shows the surface morphologies of the oxidized $\mathrm{Cu}$ substrates after the TGA measurements shown in Fig. 2. Fig. 3(a) corresponds to the surface of the un-sandblasted sample and Figs. 3(b-f) are obtained from the samples treated by sandblasting for $15 \mathrm{~s}, 45 \mathrm{~s}, 60 \mathrm{~s}, 120 \mathrm{~s}$ and $180 \mathrm{~s}$, respectively. All these sandblasted samples are oxidized under the same condition $\left(T=450{ }^{\circ} \mathrm{C}\right.$, oxygen gas flow of $60 \mathrm{ml} / \mathrm{min}$ for $1 \mathrm{~h}$ ). Fig. 3(a) shows that the oxidation of the un-sandblasted Cu results in severe surface cracking and oxide delamination, where the black areas are the surface covered by CuO which is black in color, and the orange areas are the exposed $\mathrm{Cu}$ surface due to the oxide delamination from the Cu substrate. Under the harsh oxidation condition employed in the study, the Cu surface should be severely oxidized to form a continuous oxide scale that covers the entire Cu substrate if there is no interfacial delamination. Therefore, the formation of the exposed Cu surface areas is caused by the oxide/substrate delamination. The $\mathrm{Cu}_{2} \mathrm{O} / \mathrm{Cu}$ interfacial delamination is also confirmed by the crosssectional SEM image as shown later in Fig. 4(a). As shown in Figs. 3(b-f), one can see that black areas become more continuous for the Cu substrates that are sandblasted for a longer duration. This suggests that surface cracking and interfacial delamination of the oxide layer is gradually suppressed with increasing sandblasting time. The oxide delamination from the substrate results in the exposure of fresh $\mathrm{Cu}$ surface areas to oxygen during oxidation, which results in continued oxide growth. For sandblasted $\mathrm{Cu}$, the oxide film is more continuous and thus has better self-protection property. The results demonstrate that sandblasting can effectively suppress oxide delamination, thereby promoting selfprotection property of the oxide film. This explains the TGA result that the overall oxidation rate decreases with sandblasting time as shown in Fig. 2. 
Copper forms two thermodynamically stable oxides, $\mathrm{CuO}$ and $\mathrm{Cu}_{2} \mathrm{O}$ upon reaction with oxygen and develops into a bi-layer structure with $\mathrm{CuO}$ being the top layer and $\mathrm{Cu}_{2} \mathrm{O}$ being the bottom layer in contact with the Cu substrate $[27,28]$. Fig. 4 shows representative cross-sectional SEM images of the oxidized $\mathrm{Cu}$ substrates (un-sandblasted and sandblasted surfaces) revealing the double-layer oxide growth, where the thickness for the top $\mathrm{CuO}$ layer is about $200 \mathrm{~nm}$, much thinner than the inner $\mathrm{Cu}_{2} \mathrm{O}$ layer which has a thickness of about $2.5 \mu \mathrm{m}$. It should be noted that comparing the total thicknesses of the oxide films formed on the un-sandblasted and sandblasted $\mathrm{Cu}$ substrates is not feasible because the rough $\mathrm{Cu}_{2} \mathrm{O} / \mathrm{Cu}$ interface makes it quite difficult for reliable thickness measurements of the oxide films on the sandblasted $\mathrm{Cu}$. Instead, the TGA measurements shown in Fig. 2 give a more accurate comparison of the oxidation rates for the different samples, from which the average thicknesses of the oxide films on the sandblasted Cu substrates can be determined. It has been shown that the growth of the oxide scale during the oxidation of $\mathrm{Cu}$ is controlled via outward diffusion of $\mathrm{Cu}$ cations because of the nature of point defects (i.e., $\mathrm{Cu}$ vacancies) in the $\mathrm{Cu}_{2} \mathrm{O}$ and $\mathrm{CuO}$ layers [8]. The growth of the inner $\mathrm{Cu}_{2} \mathrm{O}$ layer occurs at the expense of the inner $\mathrm{CuO}$ layer at the $\mathrm{Cu}_{2} \mathrm{O} / \mathrm{CuO}$ interface, i.e., growth of the $\mathrm{Cu}_{2} \mathrm{O}$ layer requires decomposition of the oxygen-richer $\mathrm{CuO}$ layer to obtain the necessary oxygen. Since the molar volume of $\mathrm{CuO}$ is slightly larger than that of $\mathrm{Cu}_{2} \mathrm{O}$ (the cell volumes of $\mathrm{Cu}_{2} \mathrm{O}$ and $\mathrm{CuO}$ are 77.83 $\AA^{3}$ and $81.16 \AA^{3}$, respectively), compressive stresses are generated in the CuO layer by the volume change accompanying the $\mathrm{CuO} / \mathrm{Cu}_{2} \mathrm{O}$ interface reaction, which typically stimulates $\mathrm{CuO} \mathrm{NW}$ (nanowire) formation on the outer surface $[28,29]$, as revealed in Fig. 4 . As a result, the $\mathrm{CuO} / \mathrm{Cu}_{2} \mathrm{O}$ interface stress is released by $\mathrm{CuO}$ NW formation and the $\mathrm{CuO} / \mathrm{Cu}_{2} \mathrm{O}$ interface remains intact and adherent as shown by the SEM images in Figs. 4(c and d), which are obtained from the $\mathrm{CuO} / \mathrm{Cu}_{2} \mathrm{O}$ interface regions marked by the dashed red rectangles in Figs. 4(a, b), respectively. The lengths of the NWs formed on the oxidized Cu surfaces vary from $200 \mathrm{~nm}$ to several $\mu \mathrm{m}$. EDS spectra shown in Figs. 4 (e and f) are collected from the top and second oxide layers, confirming the existence of the $\mathrm{CuO}$ and $\mathrm{Cu}_{2} \mathrm{O}$ layers. Fig. $4(\mathrm{~g})$ shows an 
XRD pattern from the un-sandblasted $\mathrm{Cu}$ sample, showing the presence of both $\mathrm{CuO}$ and $\mathrm{Cu}_{2} \mathrm{O}$ peaks. The sandblasted Cu samples show the similar XRD patterns as the un-sandblasted Cu sample.

The formation of $\mathrm{Cu}_{2} \mathrm{O}$ from the reaction $\left(\mathrm{Cu}+\mathrm{O}_{2} \rightarrow \mathrm{Cu}_{2} \mathrm{O}\right)$ at the $\mathrm{Cu}_{2} \mathrm{O} / \mathrm{Cu}$ interface results in large molar volume mismatch (the cell volumes of $\mathrm{Cu}$ and $\mathrm{Cu}_{2} \mathrm{O}$ are $47.2 \AA^{3}$ and $77.83 \AA^{3}$, respectively). The ensuring difficulties in local volume accommodation give way to the generation of large stresses in the $\mathrm{Cu}_{2} \mathrm{O} / \mathrm{Cu}$ interface region, which serve as the driving force for oxide delamination from the $\mathrm{Cu}$ substrate. This can be evidenced from Fig. $4(a)$, which shows significant delamination at the $\mathrm{Cu}_{2} \mathrm{O} / \mathrm{Cu}$ interface. This is also consistent with the optical microscopy observations as shown in Fig. 3, which demonstrate that the oxide delamination results in exposed Cu surface. However compared to the unsandblasted sample that shows significant separation at the $\mathrm{Cu}_{2} \mathrm{O} / \mathrm{Cu}$ interface, one can see from Fig. 4(b) that the $\mathrm{Cu}_{2} \mathrm{O}$ layer adheres tightly to the roughened $\mathrm{Cu}$ substrate. Pegging of the oxide film to the substrate by sandblasting provides the interlocking mechanical mechanism that results in improvement in oxide adherence and thereby better oxidation resistance as revealed in the TGA measurements shown in Fig. 2.

To confirm that the improved $\mathrm{Cu}_{2} \mathrm{O} / \mathrm{Cu}$ interfacial adhesion described above is related to sandblasting, the oxidation morphologies around individual craters generated by sandblasting are examined. Fig. 5(a) shows a 3D profile surface image of a single crater formed on a sandblasted $\mathrm{Cu}$ substrate before oxidation. The diameter of the crater is about $150 \mu \mathrm{m}$ with a ramp area, which corresponds well with the round shape and the diameter range of the spherical glass beads used for sandblasting. The crater experiences different levels of deformation from the ramp to the bottom area, as expected from the different stresses exerted during sandblasting. The stress induced-deformation increases from rim area to ramp area, and reaches maximum at the crater bottom. Fig. 5(b) shows an SEM image of an oxidized $\mathrm{Cu}$ substrate which is treated by sandblasting for $15 \mathrm{~s}$ before the oxidation at $450{ }^{\circ} \mathrm{C}$. Several craters are still visible even after the oxidation, as marked by red circles. Stress-induced 
cracks in the oxide film are also found on the surface. However, one can see that these surface cracks are terminated at the rim area of the craters, i.e., the propagation of cracks in the oxide film is stopped by the presence of craters. This suggests that the oxide film formed in the crater area has better oxide/substrate mechanical adhesion.

It can now be inferred from the observation shown in Fig. 5 that the sandblasting induced craters can inhibit cracking propagation in the oxide layer during oxidation. This corroborates well with the TGA observation shown in Fig. 2, i.e., the oxidation rate decreases with sandblasting time. Their correlation indicates that the sandblasting treatment of the $\mathrm{Cu}$ surfaces can effectively promote the oxide adhesion with the Cu substrate as seen in Fig. 4, thereby resulting in the improved self protection of the oxide film. To better elucidate the mechanical adhesion of the oxide film with the Cu substrate, we employ the nanoindentation technique to measure and evaluate the bonding energy between the oxide film and the Cu substrate. Figure 6 schematically shows the load-time pattern applied to the oxide film during the nanoindentation test, which includes a constant-rate-loading segment, a hold segment, and a constant-rate-unloading segment, as described in material and methods section.

The nanoindentation induces a complex stress field in the oxide/metal interface region, which can lead to delamination of the oxide layer at the $\mathrm{Cu}_{2} \mathrm{O} / \mathrm{Cu}$ interface. After delamination, the debonded oxide film may be suspended over the substrate under small load and can be considered as a membrane, and thus the interfacial delamination fracture energy can be analyzed by the load-depth data using the membrane theory [30-32]. The oxidation of Cu typically results in the growth of CuO NWs, as shown in the SEM image in Fig. 7(a), taken from an un-delaminated oxide film. No cracks are formed in these undelaminated surface areas. The growth of CUO NWs can be also confirmed from the cross-sectional SEM images as shown in Figs. 4(a-d). As the indenter goes down, it contacts with CuO NWs first before reaching the oxide layer, as shown schematically in Fig. $7(b)$. This results in a small force increase within a large indenter tip displacement, as observed experimentally shown in Fig. 7(c). This long flat plateau in 
the force-displacement curve is caused by the buckling of the CuO NWs. One can see that the applied load is increased only slightly for the oxide NW buckling and is very small compared to the maximum load that results in the film delamination. Therefore, the effect from the NWs is negligible in the loaddisplacement measurements on the oxide film delamination.

Fig. 8(a) shows an example of our results of the nanoindentation measurements made on the oxidized $\mathrm{Cu}$ substrate that is treated by sandblasting for $120 \mathrm{~s}$ before the oxidation at $450{ }^{\circ} \mathrm{C}$ for $1 \mathrm{~h}$. The nanoindentation consists of loading, holding, and unloading segments. No obvious failure event is observed in the load-displacement curve during loading. The unloading curve reveals that there is an elbow followed by a linear load-depth recovery. During unloading, the obvious change in the slope of the curve is caused by the delaminated oxide film pushing upwards onto the indenter. The linear recovery observed at the end of unloading is attributed to the spontaneous opening caused by the delamination at the $\mathrm{Cu}_{2} \mathrm{O} / \mathrm{Cu}$ interface during unloading. The delamination induced slope changes or extra linear recovery have also been observed in other experimental systems [30-33] as well as in numerical simulations $[34,35]$. The debonded oxide film is separated from the Cu substrate and acts as a membrane with an effective spring constant, as schematically shown in Fig. 8(b). As mentioned earlier, the $\mathrm{CuO} / \mathrm{Cu}_{2} \mathrm{O}$ interfacial bonding is strong because of the relaxation of the $\mathrm{CuO} / \mathrm{Cu}_{2} \mathrm{O}$ interfacial stress by $\mathrm{CuONW}$ formation, the delamination occurs at the interface between the $\mathrm{Cu}_{2} \mathrm{O}$ layer and the $\mathrm{Cu}$ substrate. The linear recovery behavior observed in the nanoindentation measurements is the response of the delamination at the $\mathrm{Cu}_{2} \mathrm{O} / \mathrm{Cu}$ interface.

The interfacial fracture energy, which is the resistance to delamination, is used as a measurement of the practical work of the interfacial adhesion. For the case of no buckling, the indentation-induced stress in the suspended film can be evaluated by the membrane theory [30, 31]. The interfacial fracture energy $G$ can be determined without estimating the delamination length and can be expressed as $[32,36]$, 


$$
G=\frac{K_{c}^{2}}{32 \pi^{2} t E_{f}^{*}}
$$

where $E_{f}^{*}, t$ and $K_{c}$ are the reduced modulus, the thickness of the oxide film and the effective spring constant of suspended oxide film in the unloading segment, respectively. It is noted that $E_{f}^{*}$ denotes the oxide film's reduced modulus as $E_{f}^{*}=E_{f} /\left(1-v_{f}^{2}\right)$, where $E_{f}$ and $v_{f}$ are Young's modulus and Poisson's ratio, respectively. The oxide film Poisson's ratio $v_{f}=0.455$ is adopted [34]. This is a convenient method to evaluate the interfacial fracture energy $G$ because the values of $K_{c}$ and $E_{f}^{*}$ can be directly obtained from the experimental results. The value of $K_{c}$ is $7.73 \mu \mathrm{N} / \mathrm{nm}$ as determined from the linear recovery segment during unloading shown in Fig. 8(a). By using the thickness of the oxide films and the reduced modulus obtained from the nanoindentation test $\left(\mathrm{t}=1.98 \mu \mathrm{m}, E_{f}^{*}=25.4 \mathrm{GPa}\right)$, the interfacial fracture energy of the $\mathrm{Cu}_{2} \mathrm{O}$ film on the $\mathrm{Cu}$ substrate can be calculated by Equation (1). Similar nanoindentation tests are performed on different locations of the oxidized Cu surface, from which an average value of the interfacial fracture energy is obtained. For instance, the interfacial fracture energy for the oxide film formed on the Cu substrate sandblasted for $120 \mathrm{~s}$ is $3.1 \mathrm{~J} / \mathrm{m}^{2}$.

Similar nanoindentation tests are also performed on a number of the Cu substrates that are first treated by sandblasting for different durations and then oxidized under the same oxidation condition as shown in the TGA measurements (Fig. 2). It is worth noting that not all cases show oxide film delamination in our nano-indentation measurements. For instance, the oxide layer on the Cu substrate which is treated by sandblasting for $180 \mathrm{~s}$ still bonds with the substrate during the unloading segment, as shown schematically in Fig. 9(a). The blue curve in Fig. 9(b) shows a representative measurement of the bonded film. During loading and unloading segments, no obvious failure event is observed, which can be ascribed to the strong $\mathrm{Cu}_{2} \mathrm{O} / \mathrm{Cu}$ interface. Since the NWs induced long flat plateau in the loaddisplacement curves (i.e., Fig. 7(c), 8(a) and 9(b)) is negligible in the load-displacement measurements on the oxide film delamination, NWs are not included in the schematic drawings of Fig. 8(b) and 9(a) in 
order to show the failure event of the oxide film more clearly. Table 1 lists the key measured and calculated data about the oxide thin films. From Table 1, we can find that the Young's moduli remain nearly constant at around $36 \mathrm{GPa}$ for the oxide films formed on the different $\mathrm{Cu}$ substrates, which is consistent with the reported value of the Young's modulus for $\mathrm{Cu}_{2} \mathrm{O}[37,38]$. The table shows the $\mathrm{Cu}_{2} \mathrm{O} / \mathrm{Cu}$ interfacial fracture energies show correlation with sandblasting time, i.e., the interfacial fracture energy increases with sandblasting time. As shown earlier, the substrate roughness increases with sandblasting treatment time. Thus, the effect of the surface roughness has a marked effect on the energy dissipation during debonding. Nano-indentation measurements are also performed on the oxidized Cu substrates which are sandblasted for 135 s, $150 \mathrm{~s}$ and $165 \mathrm{~s}$, respectively, prior to their oxidation. For all these samples, the oxide films show very good adhesion with the sandblasted $\mathrm{Cu}$ substrates and no obvious failure events are observed in our nano-indentation tests. The possible reason is that the maximum load of indentation $(7 \mathrm{mN})$ is not sufficiently large to induce the delamination between the oxide film and the $\mathrm{Cu}$ substrate owing to the enhanced $\mathrm{Cu}_{2} \mathrm{O} / \mathrm{Cu}$ interfacial adhesion.

The increased $\mathrm{Cu}_{2} \mathrm{O} / \mathrm{Cu}$ interfacial fracture energy for the sandblasted $\mathrm{Cu}$ can be ascribed to the concave shape of craters formed on the Cu surfaces. Due to the large volume increase associated with the oxide formation, the oxidation of copper results in large compression stress (e.g., growth stress) in the oxide film. In addition, the thermal expansion coefficients of $\mathrm{Cu}_{2} \mathrm{O}$ and $\mathrm{Cu}$ are $1.9 \times 10^{-6}{ }^{\circ} \mathrm{C}^{-1}$ and $17 \times$ $10^{-6}{ }^{\circ} \mathrm{C}^{-1}$, respectively. Because of the thermal expansion mismatch, a thermal stress (compressive) is also generated in the oxide film after the sample is cooled down to room temperature. Thus, the oxide film is under compression for both the growth and thermal stresses. The concave shape of the craters induced by sandblasting facilitates the establishment of a net downward force from the compressive stresses in the film to force the film to adhere to the substrate, as shown schematically in Fig. 10. This also corroborates well with the SEM observation as shown in Fig. 5(b), which shows that the crack 
propagation in the oxide film stops near the crater region. This is the mechanics origin behind the observed results of the improved oxide/substrate adhesion induced by surface sandblasting. Another contribution for the improved oxide adhesion with the sandblasted substrates is the sandblasting induced increase in surface area by which any type of physical or chemical bonding between the oxide film and the Cu substrate becomes more effective.

\section{Conclusion}

We have studied the effect of $\mathrm{Cu}$ surface roughening induced by sandblasting on the oxidation behavior of $\mathrm{Cu}$. Our results demonstrate that increasing the sandblasting treatment time reduces the oxide film growth and suppress the oxide film delamination from the $\mathrm{Cu}$ substrate. Our nanoindentation measurements reveal that the $\mathrm{Cu}_{2} \mathrm{O} / \mathrm{Cu}$ interfacial fracture energy increases with sandblasting time. All these results demonstrate that increasing the surface roughness of the Cu substrate can effectively improve the oxide/substrate interfacial adhesion, thereby resulting in better self-protection of the oxide film. The improved oxide/Cu interfacial adhesion is ascribed to the concave shape of craters generated by sandblasting, which produces a net downward force from the compressive stresses in the oxide film to force the film to adhere to the substrate. These results may have broader applicability in manipulating surface oxidation kinetics and the oxide/metal adhesion by modifying the surface roughness of the metals via the simple mechanical approach. The present work is solely focused on the interface between $\mathrm{Cu}$ substrate and the oxide film. Further investigations to elucidate the effect of sandblasting on the performance of the actual system, i.e., the Cu-EMC assembly, are needed but are beyond the present study.

\section{Acknowledgements:}


Research supported by the U.S. Department of Energy, Office of Basic Energy Sciences, Division of Materials Sciences and Engineering under Award No. DE-SC0001135. 


\section{References:}

[1] A. Chen, R.H.-Y. Lo, Semiconductor Packaging: Materials Interaction and Reliability, CRC Press, 2011. [2] M. Lebbai, J. Kim, M. Yuen, Effects of dimple and metal coating on interfacial adhesion in plastic packages, Journal of Electronic Materials, 32 (2003) 564-573.

[3] C. Gan, E. Ng, B. Chan, U. Hashim, Reliability challenges of Cu wire deployment in flash memory packaging, in: Microsystems, Packaging, Assembly and Circuits Technology Conference (IMPACT), 2012 7th International, IEEE, 2012, pp. 236-239.

[4] T. Ishizaki, T. Satoh, A. Kuno, A. Tane, M. Yanase, F. Osawa, Y. Yamada, Thermal characterizations of Cu nanoparticle joints for power semiconductor devices, Microelectronics Reliability, 53 (2013) 15431547.

[5] S. Murali, J. Yeung, R. Perez, Alloyed copper bonding wire with homogeneous microstructure, in: Electronic Manufacturing Technology Symposium (IEMT), 2012 35th IEEE/CPMT International, IEEE, 2012, pp. 1-6.

[6] D.A. Hutt, C. Liu, Oxidation protection of copper surfaces using self-assembled monolayers of octadecanethiol, Applied Surface Science, 252 (2005) 400-411.

[7] S. Cho, K. Paik, Oxidation studies on a Cu-base leadframe alloy between $150 \mathrm{C}$ and $300 \mathrm{C}$, Scripta Materialia, 38 (1998) 1149-1154.

[8] N. Birks, G.H. Meier, F.S. Pettit, Introduction to the high temperature oxidation of metals, Cambridge University Press, 2006.

[9] D. Cocke, G. Chuah, N. Kruse, J. Block, Copper oxidation and surface copper oxide stability investigated by pulsed field desorption mass spectrometry, Applied Surface Science, 84 (1995) 153-161. [10] W. Zhang, W. Luo, A. Hu, M. Li, Adhesion improvement of Cu-based substrate and epoxy molding compound interface by hierarchical structure preparation, Microelectronics Reliability, 52 (2012) 11571164.

[11] L.T. Nguyen, Reliability of Postmolded IC Packages, Journal of Electronic Packaging, 115 (1993) 346355.

[12] F. Xing, F. Qiang, W. Jun, Y. Hongkun, S. Xuefeng, Effect of Cu Lead-Frame Oxidation Time on Cu/EMC Interfaces in Power Devices, Semiconductor Technology, 2 (2010) 010.

[13] W. Zhang, Q. Lu, T. Hang, M. Li, D. Mao, Electroless plating copper cones on leadframe to improve the adhesion with epoxy molding compound, in: Electronic Packaging Technology and High Density Packaging (ICEPT-HDP), 2012 13th International Conference on, IEEE, 2012, pp. 259-263.

[14] H.-Y. Lee, J. Qu, An interpretation of the failure paths of roughened metal/polymerinterfaces, Metals and Materials International, 7 (2001) 101-105.

[15] H. Y. Lee, G.S. Park, Failure paths at copper-base leadframe/epoxy molding compound interfaces, Journal of Materials Science, 37 (2002) 4247-4257.

[16] Narasimalu Srikanth, Lewis Chan, C.J.V. III, Adhesion improvement of EMC-leadframe interface using brown oxide promoters, Thin Solid Films, 504 (2006) 397- 400.

[17] M. Ni, M. Li, D. Mao, Adhesion improvement of Epoxy Molding Compound - Pd Preplated leadframe interface using shaped nickel layers, Microelectronics Reliability, 52 (2012) 206-211. [18] T. Hang, H. Ling, Z. Xiu, M. Li, D. Mao, Study on the adhesion between epoxy molding compound and nanocone-arrayed Pd preplated leadframes, Journal of Electronic Materials, 36 (2007) 1594-1598.

[19] A. Oláh, H. Hillborg, G.J. Vancso, Hydrophobic recovery of UV/ozone treated poly (dimethylsiloxane): adhesion studies by contact mechanics and mechanism of surface modification, Applied Surface Science, 239 (2005) 410-423.

[20] D.J. Young, High temperature oxidation and corrosion of metals, Access Online via Elsevier, 2008.

[21] A. Volinsky, N. Moody, W. Gerberich, Interfacial toughness measurements for thin films on substrates, Acta Materialia, 50 (2002) 441-466. 
[22] J. Rakowski, G. Meier, F. Pettit, F. Dettenwanger, E. Schumann, M. Rühle, The effect of surface preparation on the oxidation behavior of gamma TiAl-base intermetallic alloys, Scripta Materialia, 35 (1996) 1417-1422.

[23] J. Yuan, X. Wu, W. Wang, S. Zhu, F. Wang, The Effect of Surface Finish on the Scaling Behavior of Stainless Steel in Steam and Supercritical Water, Oxidation of Metals, 79 (2013) 541-551.

[24] R. Naraparaju, H.-J. Christ, F. Renner, A. Kostka, Effect of shot-peening on the oxidation behaviour of boiler steels, Oxidation of Metals, 76 (2011) 233-245.

[25] X.S. Guan, Z.F. Dong, D.Y. Li, Surface nanocrystallization by sandblasting and annealing for improved mechanical and tribological properties, Nanotechnology, 16 (2005) 2963-2971.

[26] I. Nikitin, I. Altenberger, H.J. Maier, B. Scholtes, Mechanical and thermal stability of mechanically induced near-surface nanostructures, Materials Science and Engineering: A, 403 (2005) 318-327.

[27] R. Mema, L. Yuan, Q.T. Du, Y.Q. Wang, G.W. Zhou, Effect of surface stresses on CuO nanowire growth in the thermal oxidation of copper, Chemical Physics Letters, 512 (2011) 87-91.

[28] L. Yuan, Y.Q. Wang, R. Mema, G.W. Zhou, Driving force and growth mechanism for spontaneous oxide nanowire formation during the thermal oxidation of metals, Acta Materialia, 59 (2011) 2491-2500.

[29] L. Yuan, G.W. Zhou, Enhanced CuO nanowire formation by thermal oxidation of roughened copper, Journal of The Electrochemical Society, 159 (2012) C1.

[30] S. Hainsworth, M. McGurk, T. Page, The effect of coating cracking on the indentation response of thin hard-coated systems, Surface and Coatings Technology, 102 (1998) 97-107.

[31] P.J. Wei, S.B. Chio, W.L. Liang, J.F. Lin, Determining buckling strain energy release rate through indentation-induced delamination, Thin Solid Films, 519 (2011) 4889-4893.

[32] P.J. Wei, W.L. Liang, C.F. Ai, J.F. Lin, A new method for determining the strain energy release rate of an interface via force-depth data of nanoindentation tests, Nanotechnology, 20 (2009) 025701.

[33] J. Chen, S. Bull, Indentation fracture and toughness assessment for thin optical coatings on glass, Journal of Physics D: Applied Physics, 40 (2007) 5401.

[34] A. Abdul-Baqi, E. Van der Giessen, Delamination of a strong film from a ductile substrate during indentation unloading, Journal of Materials Research, 16 (2001) 1396-1407.

[35] J. Chen, S. Bull, Finite element analysis of contact induced adhesion failure in multilayer coatings with weak interfaces, Thin Solid Films, 517 (2009) 3704-3711.

[36] D. Marshall, A. Evans, Measurement of adherence of residually stressed thin films by indentation. I. Mechanics of interface delamination, Journal of Applied Physics, 56 (1984) 2632-2638.

[37] G.W. Zhou, J.C. Yang, Formation of Quasi-One-Dimensional $\mathrm{Cu}_{2} \mathrm{O}$ Structures by in situ Oxidation of Cu (100), Physical review letters, 89 (2002) 106101.

[38] H.J. Frost, M.F. Ashby, Deformation mechanism maps: the plasticity and creep of metals and ceramics, Pergamon press, 1982. 
Table:

Table 1: List of experimentally measured and calculated parameters for the $\mathrm{Cu}$ oxide film and the $\mathrm{Cu}_{2} \mathrm{O} / \mathrm{Cu}$ interface

\begin{tabular}{ccccccc}
\hline $\begin{array}{c}\text { Sample } \\
\#\end{array}$ & $\begin{array}{c}\text { Sandblasting } \\
\text { time }(\mathrm{s})\end{array}$ & $\begin{array}{c}\text { Oxide } \\
\text { film } \\
\text { thickness } \\
t(\mu \mathrm{m})\end{array}$ & $\begin{array}{c}\text { Reduced } \\
\text { modulus } E_{f}^{*} \\
\text { of the oxide } \\
\text { film }(\mathrm{GPa})\end{array}$ & $\begin{array}{c}\text { Young's } \\
\text { modulus of the } \\
\text { oxide film } \\
(\mathrm{GPa})\end{array}$ & $\begin{array}{c}\text { Effective spring } \\
\text { constant } \mathrm{K}_{\mathrm{c}} \\
(\mu \mathrm{N} / \mathrm{nm})\end{array}$ & $\begin{array}{c}\text { Interfacial } \\
\text { fracture } \\
\text { energy } G \\
\left(\mathrm{~J} / \mathrm{m}^{2}\right)\end{array}$ \\
\hline 1 & 0 & $3.06 \pm 0.15$ & $24.7 \pm 4.4$ & $31.1 \pm 5.5$ & $0.91 \pm 0.13$ & $0.035 \pm 0.005$ \\
2 & 15 & $2.66 \pm 0.08$ & $32.1 \pm 6.5$ & $40.4 \pm 8.2$ & $1.34 \pm 0.21$ & $0.067 \pm 0.012$ \\
3 & 45 & $2.46 \pm 0.1$ & $27.3 \pm 3.3$ & $34.5 \pm 4.2$ & $2.53 \pm 0.26$ & $0.30 \pm 0.03$ \\
4 & 60 & $2.29 \pm 0.05$ & $31.0 \pm 6.7$ & $39.0 \pm 8.5$ & $5.51 \pm 0.57$ & $1.36 \pm 0.25$ \\
5 & 120 & $1.98 \pm 0.07$ & $27.9 \pm 4.6$ & $35.2 \pm 5.8$ & $7.36 \pm 0.78$ & $3.10 \pm 0.43$ \\
6 & 135 & $1.89 \pm 0.04$ & $25.6 \pm 3.7$ & $32.3 \pm 4.6$ & $\mathrm{NA}$ & $\mathrm{NA}$ \\
7 & 150 & $1.82 \pm 0.05$ & $30.3 \pm 4.2$ & $38.3 \pm 5.3$ & $\mathrm{NA}$ & $\mathrm{NA}$ \\
8 & 165 & $1.79 \pm 0.05$ & $31.6 \pm 5.9$ & $39.8 \pm 7.8$ & $\mathrm{NA}$ & $\mathrm{NA}$ \\
9 & 180 & $1.77 \pm 0.03$ & $26.0 \pm 5.2$ & $32.8 \pm 6.6$ & $\mathrm{NA}$ & $\mathrm{NA}$ \\
\hline
\end{tabular}




\section{Figure captions:}

Fig. 1: 3D surface images taken by optical profilometer showing the surface morphology of the $\mathrm{Cu}$ surfaces treated by sandblasting for (a) $0 \mathrm{~s}$, (b) $15 \mathrm{~s}$, (c) $45 \mathrm{~s}$, (d) $120 \mathrm{~s}$, and (e) $180 \mathrm{~s}$, respectively. The size of the image area is $186 \mu \mathrm{m} \times 244 \mu \mathrm{m}$. (f) Mean roughness (roughness average Ra) measured from the 3D profilometer images vs. sandblasting time.

Fig. 2: TGA measurements of mass gains during the oxidation of sandblasted $\mathrm{Cu}$ samples during the oxidation at $\mathrm{T}=450{ }^{\circ} \mathrm{C}$ with an oxygen flow of $60 \mathrm{ml} / \mathrm{min}$. Before the oxidation, the bare $\mathrm{Cu}$ surfaces are treated by sandblasting for different durations ranging from (a) $0 \mathrm{~s}$, (b) $15 \mathrm{~s}$, (c) $45 \mathrm{~s}$, (d) $60 \mathrm{~s}$, (c) $120 \mathrm{~s}$, (f) 180 s, respectively.

Fig. 3: Optical images of the Cu surfaces that are first treated by sandblasting for (a) $0 \mathrm{~s}$, (b) $15 \mathrm{~s}$, (c) $45 \mathrm{~s}$, (d) $60 \mathrm{~s}$, (c) $120 \mathrm{~s}$, (f) $180 \mathrm{~s}$, respectively, followed by oxidation at T $=450{ }^{\circ} \mathrm{C}$ for $1 \mathrm{~h}$ in an oxygen flow of $60 \mathrm{ml} / \mathrm{min}$. Black area is $\mathrm{CuO}$, and orange area is $\mathrm{Cu}$. Prior to oxidation.

Fig. 4: Cross-sectional SEM images of the Cu substrates oxidized at $450{ }^{\circ} \mathrm{C}$ for $1 \mathrm{~h}$ in a flow of $60 \mathrm{ml} / \mathrm{min}$ of oxygen: (a) un-sandblasted Cu substrate; (b) the Cu substrate that is treated by sandblasting for $45 \mathrm{~s}$ before the oxidation; (c, d) zoom-in SEM images of the red dashed boxes shown in (a) and (b), respectively; (e, f) EDS results collecting from $\mathrm{CuO}$ layer (e) and $\mathrm{Cu}_{2} \mathrm{O}$ layer (f), respectively; (g) XRD pattern from the oxidized un-sandblasted Cu substrate.

Fig. 5: (a) 3D profile image of a single crater formed by sandblasting for $3 \mathrm{~s}$. (b) SEM image of the oxidized Cu substrate that is first treated by sandblasting for $15 \mathrm{~s}$ followed by oxidation at $450{ }^{\circ} \mathrm{C}$ for $1 \mathrm{~h}$ 
in a flow of oxygen $(60 \mathrm{ml} / \mathrm{min})$, red circles mark the presence of craters on the oxidized surface. Cracks in the oxide film are observed to terminate at the cater edge.

Fig. 6: Schematic illustration of the load-time pattern applied to the oxide film during the nanoindentation test.

Fig. 7: (a) SEM image showing the formation of CuO NWs on the Cu surface oxidized at $450{ }^{\circ} \mathrm{C}$ for $1 \mathrm{~h}$ in a flow of oxygen $(60 \mathrm{ml} / \mathrm{min})$; (b) Schematic showing that the contact of the nanoindenter with CuO NWs during the loading process, which results in the buckling of the NWs with a slightly increased force load; (c) experimental nanoindentation load-displacement curves for a two-stage behavior; the inset figure shows the load-displacement curve for the contact between NWs and the indenter.

Fig. 8: (a) A representative experimental nanoindentation load-displacement curve showing the debonding of the oxide film from the $\mathrm{Cu}$ substrate during the unloading segment. (b) Schematic representation showing the geometry of the debonding case during the unloading segment.

Fig. 9: (a) The schematic drawing shows the geometry of the bonding case during the unloading segment. (b) Experimental load-displacement curves obtained from the nanoindentation measurements made on the $\mathrm{Cu}$ substrate that is first treated by sandblasting for $180 \mathrm{~s}$ followed by oxidation at $450{ }^{\circ} \mathrm{C}$ for $1 \mathrm{~h}$ in an oxygen flow of $60 \mathrm{ml} / \mathrm{min}$.

Fig. 10: Schematic diagram of the cross-section of an oxide film grown on a crater formed by sandblasting. The mismatch in mole volumes and thermal expansion coefficients between $\mathrm{Cu}$ and the 
oxide film creates compressive stress in the oxide film. The concave shape of the crater produces a net downward force that forces the film to adhere to the substrate. 

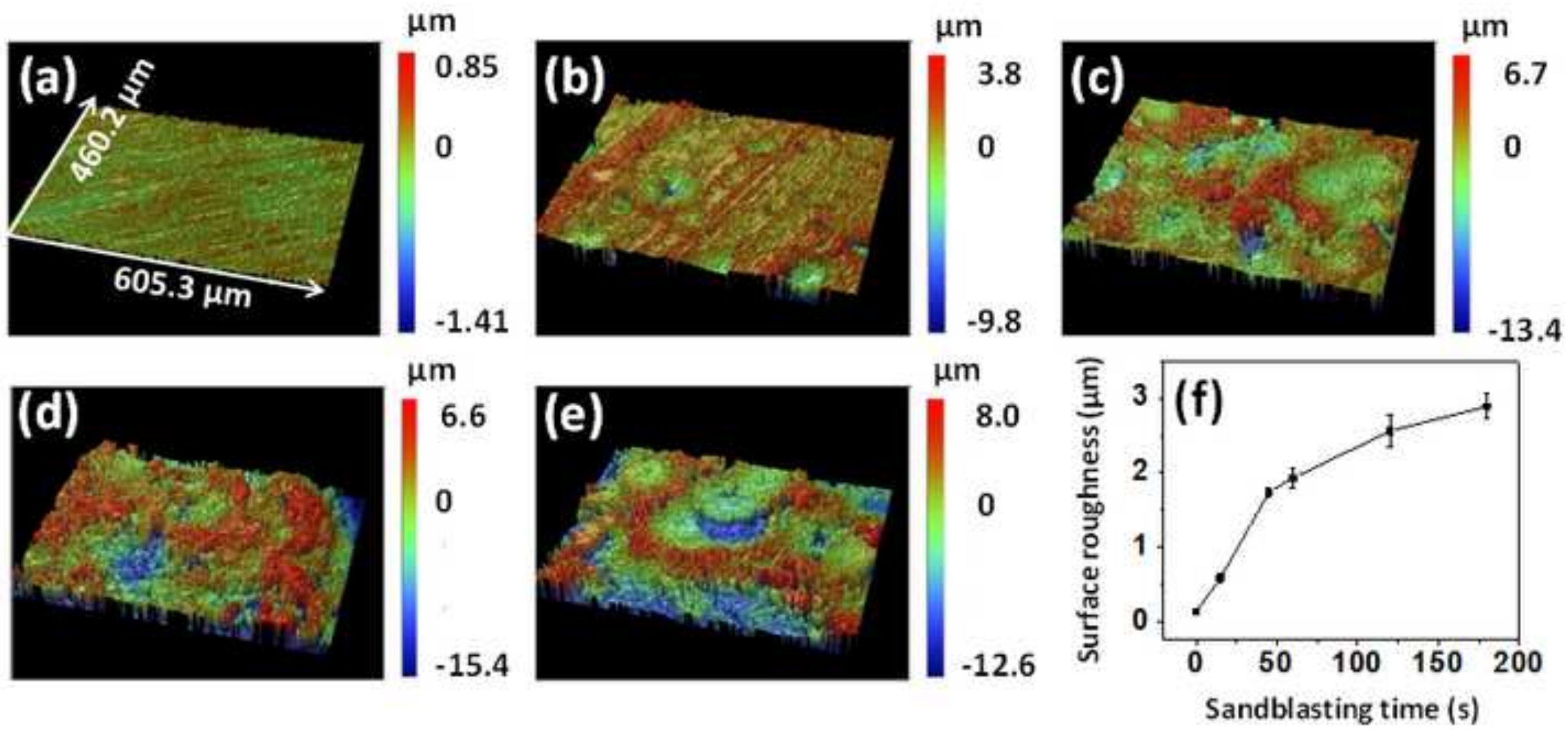


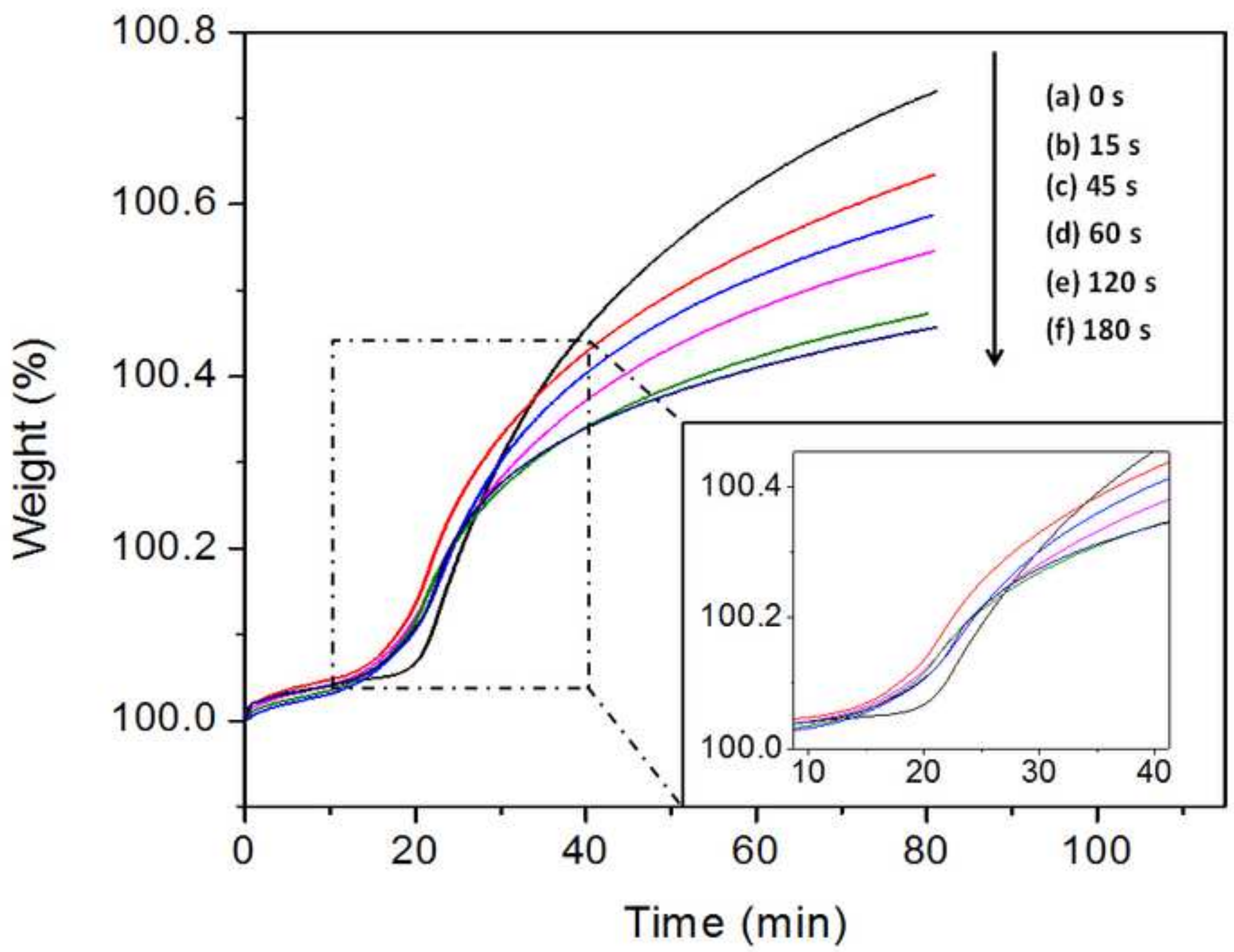



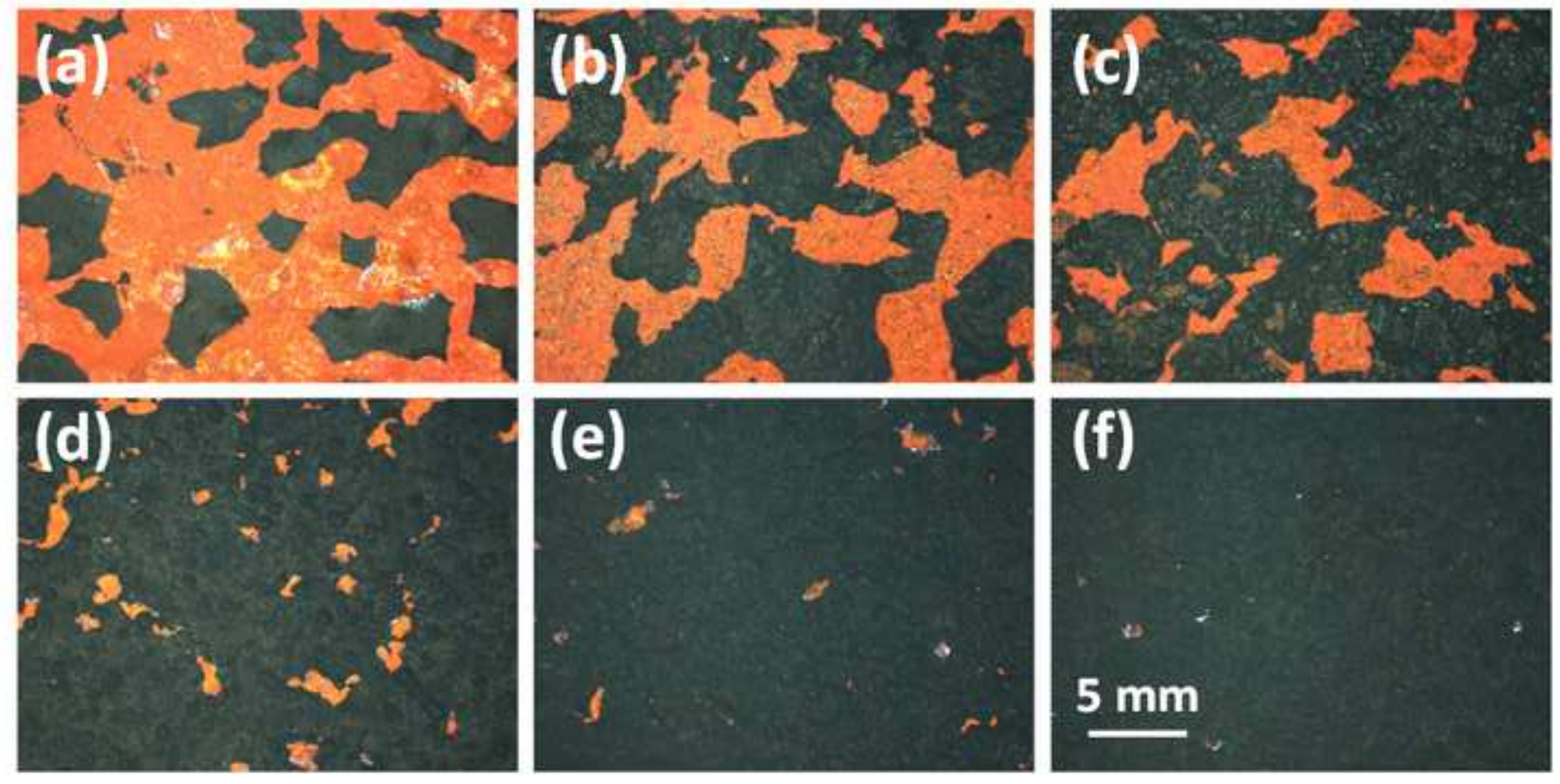

(e)

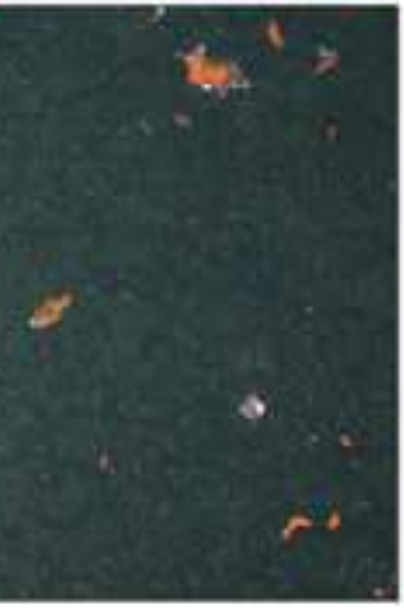
$s^{3}$

ck

I

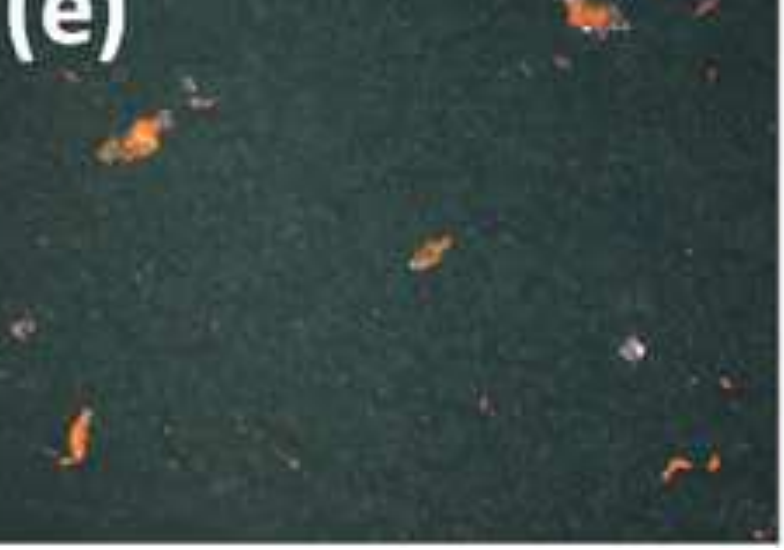

(f)

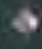

$5 \mathrm{~mm}$

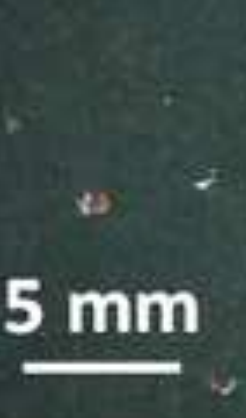



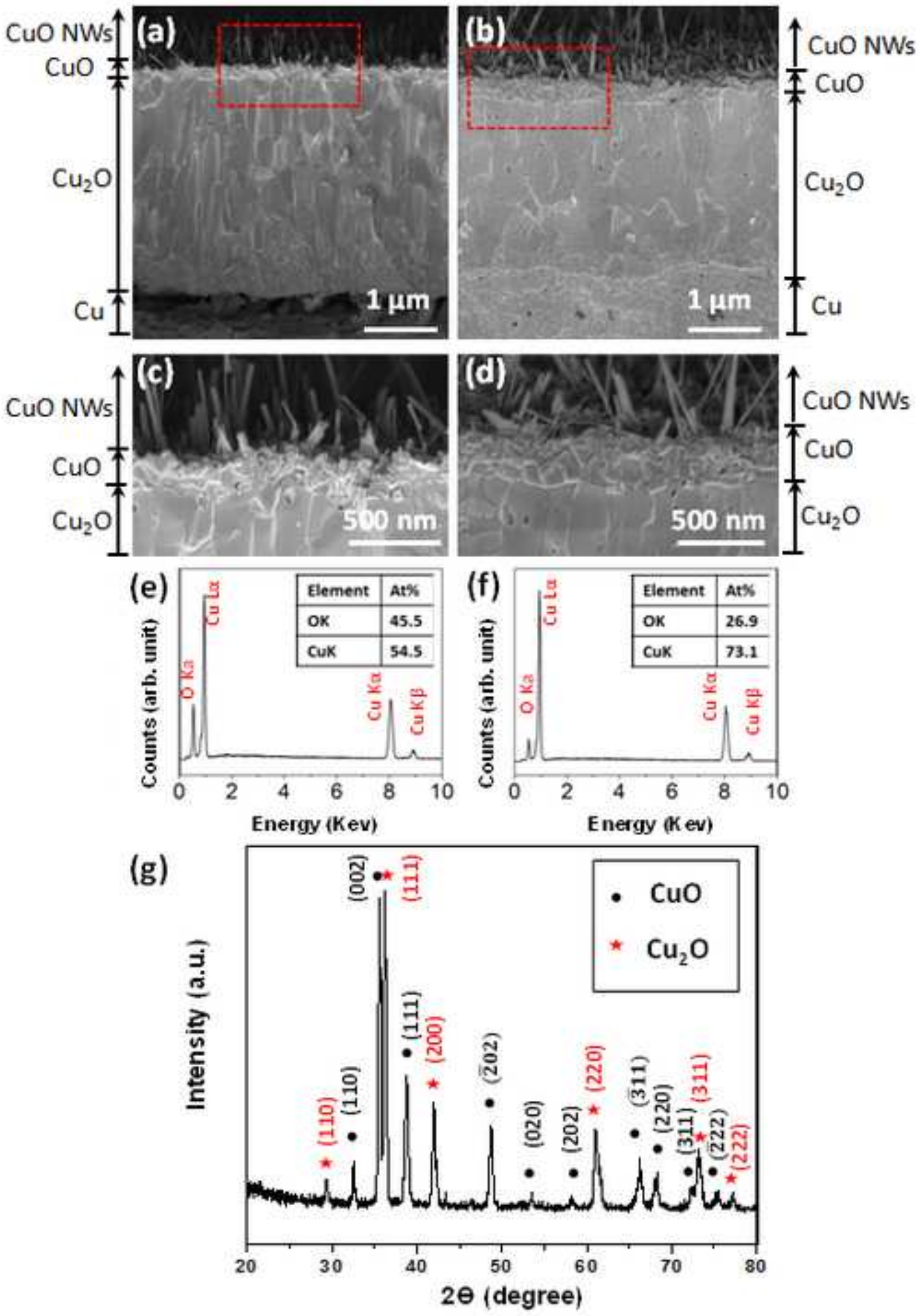

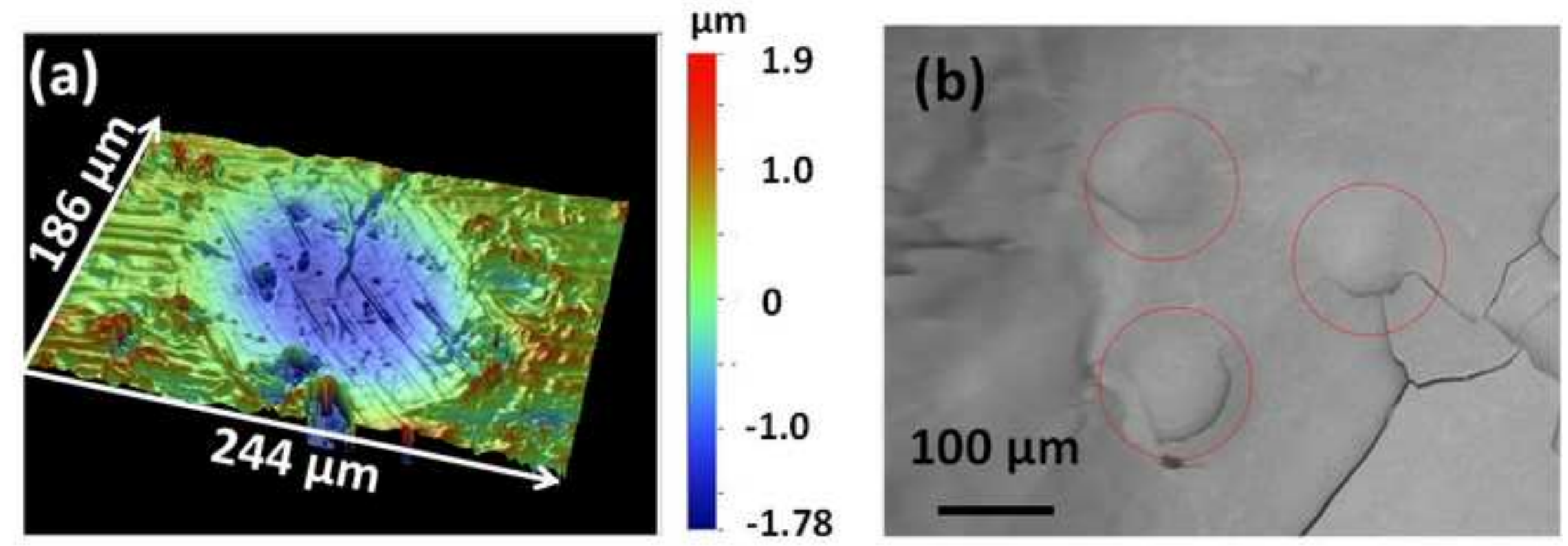


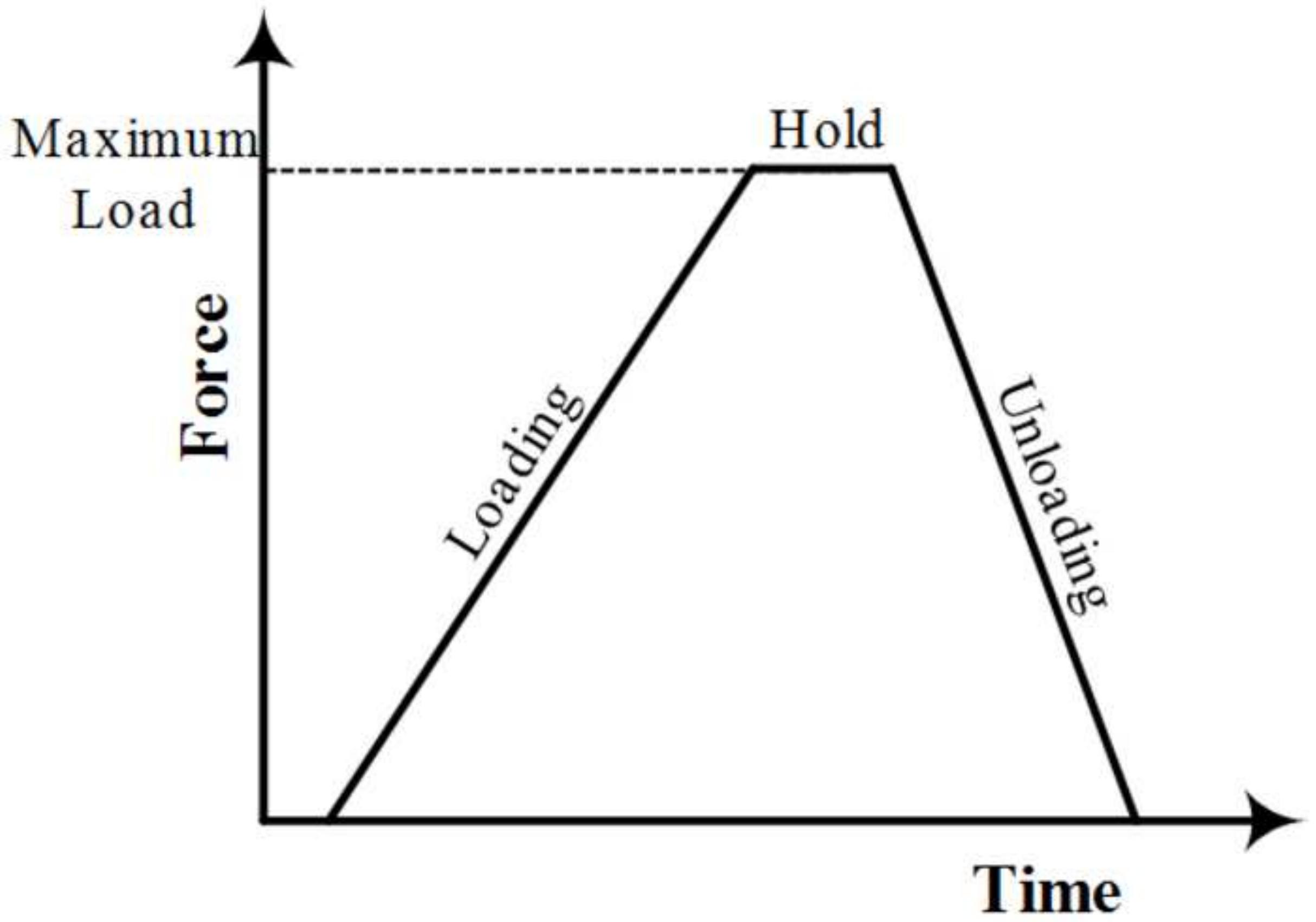



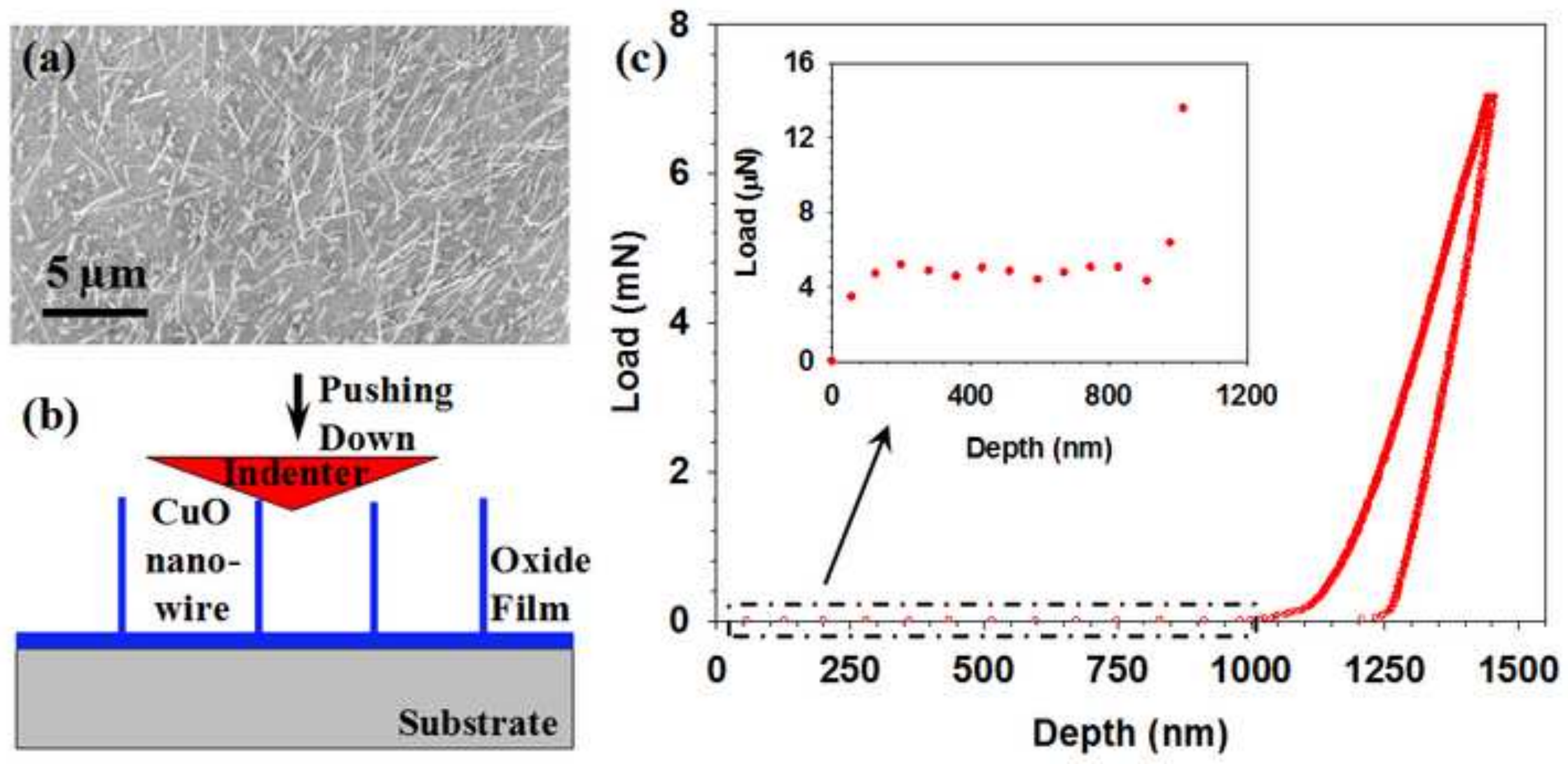


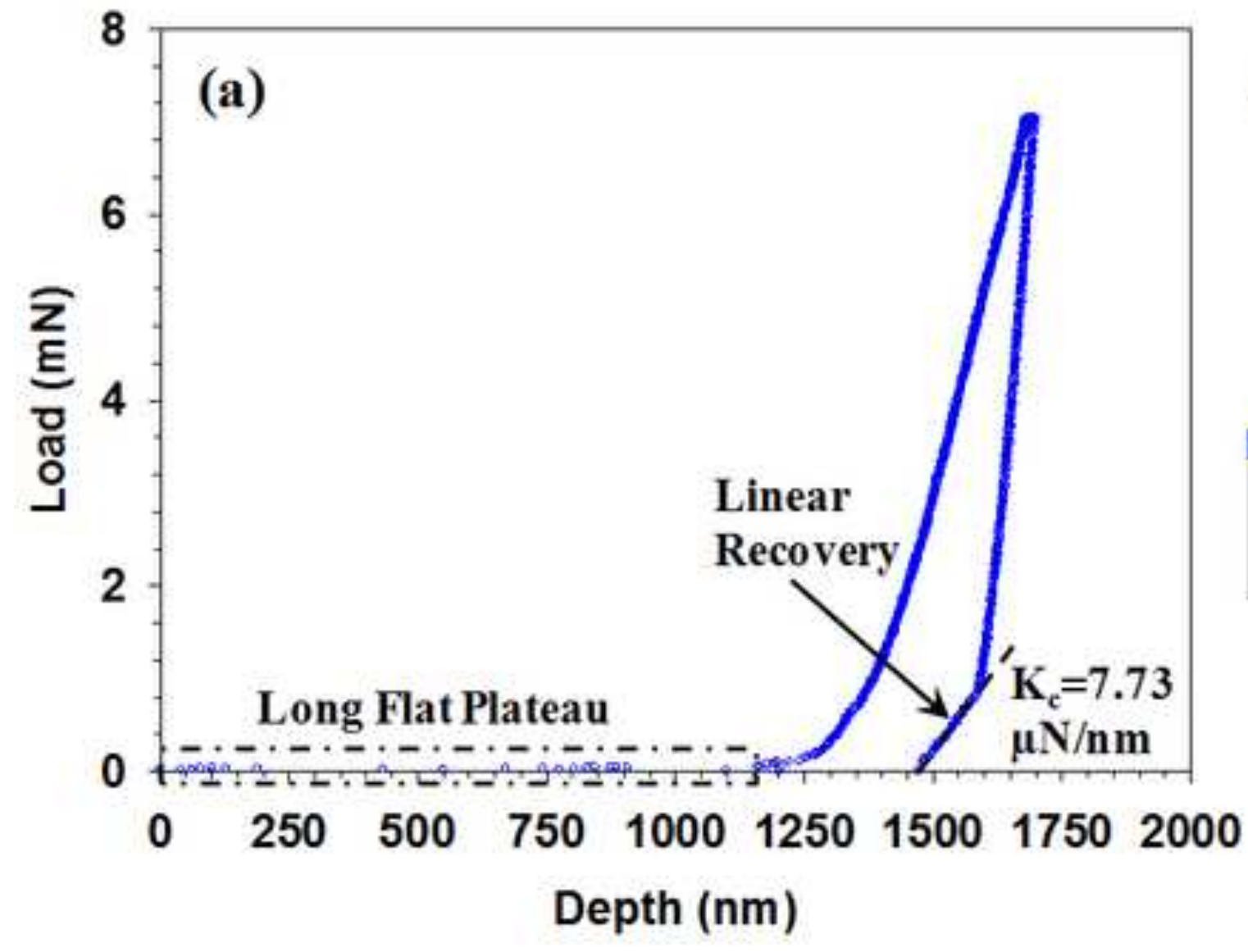

(b)

Pushing Out T

Oxide Film

Debonding

Substrate

Depth (nm) 
(a)

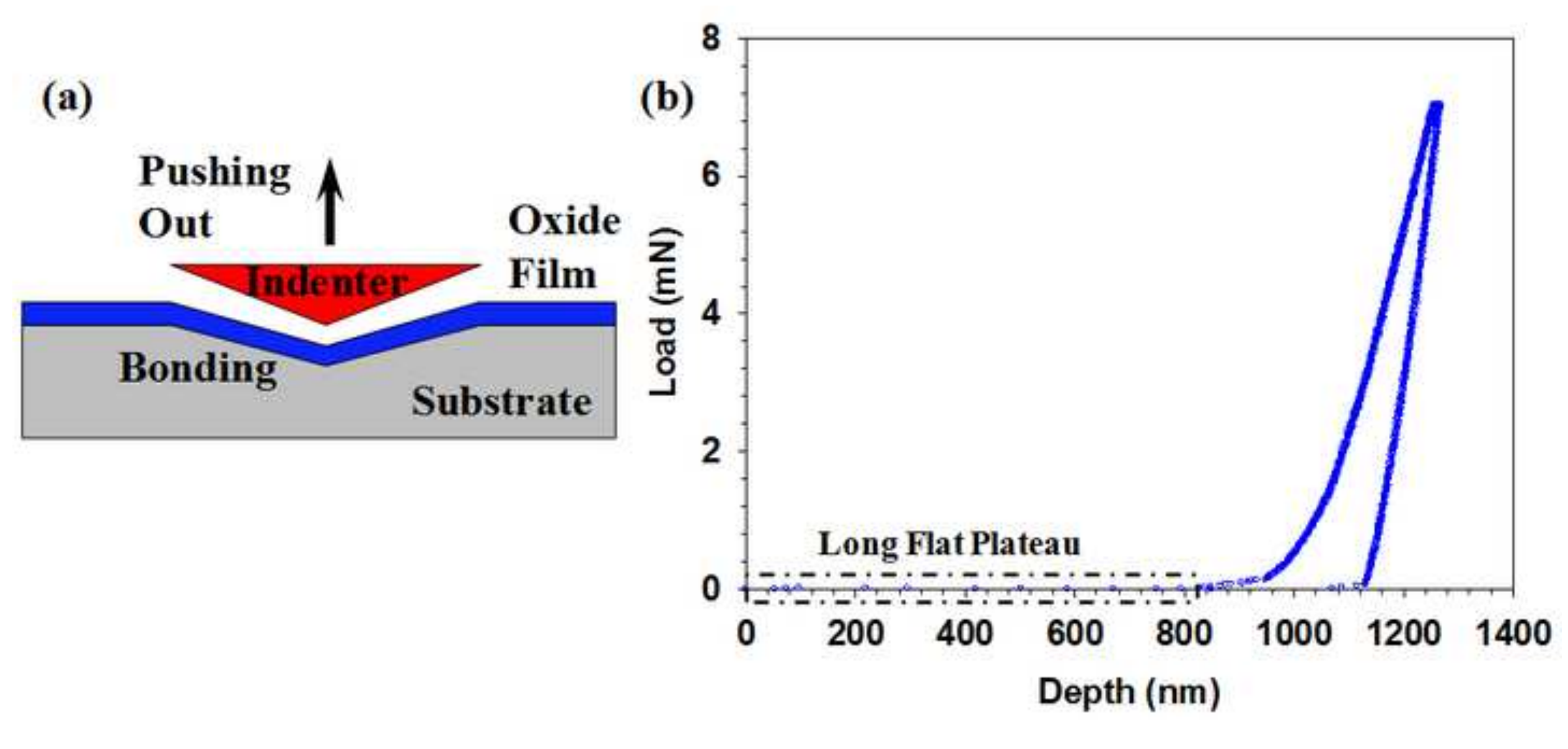

\section{Substrate}

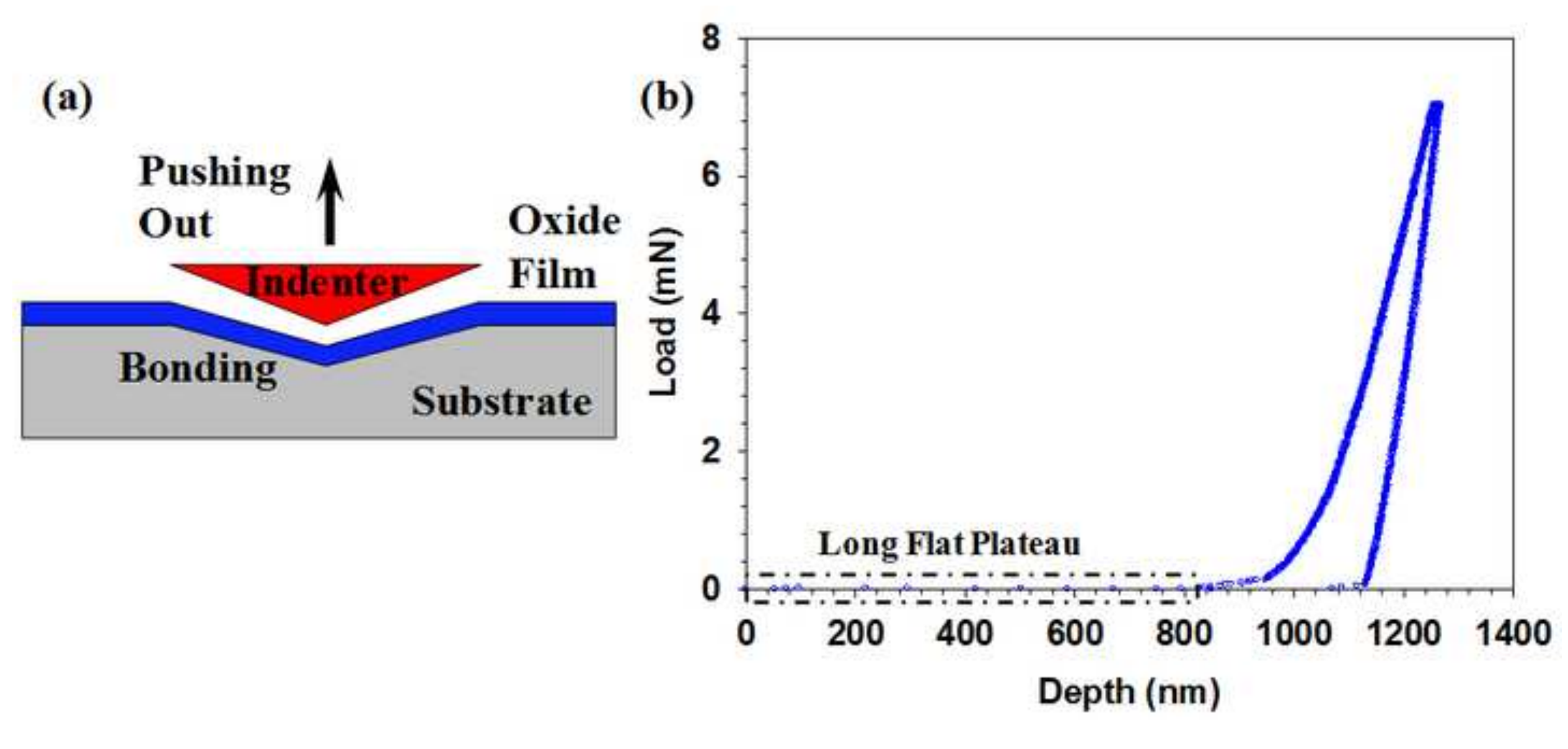




\section{Compressive}

Stress

\section{Oxide}

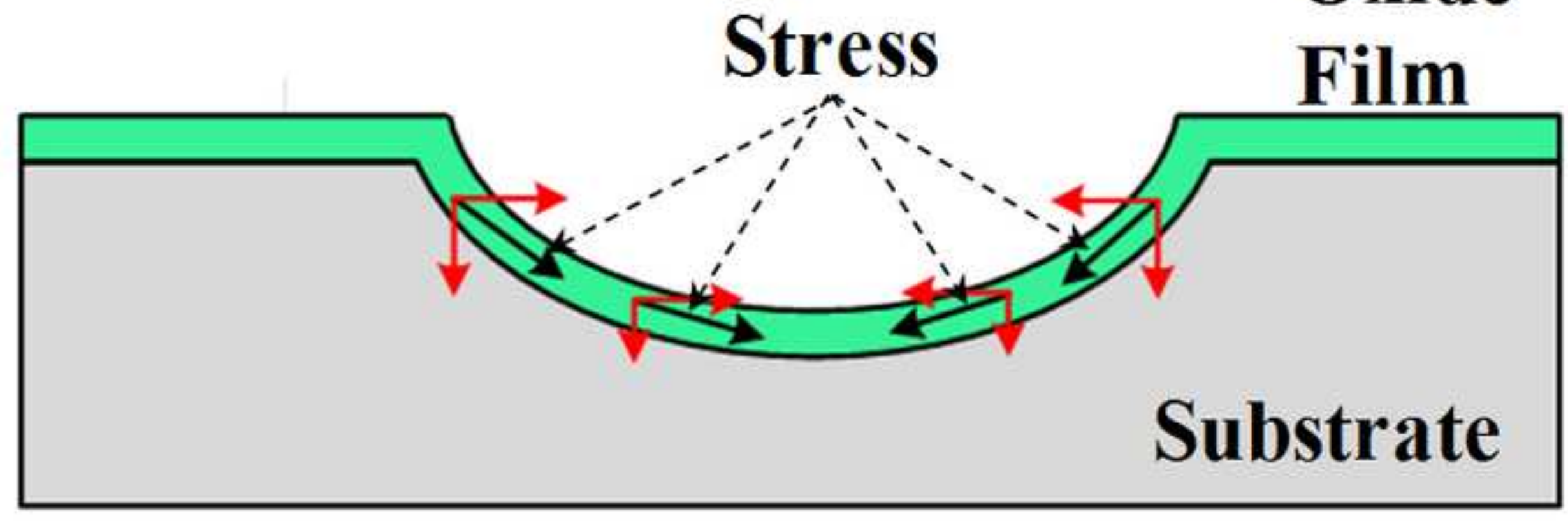

